\title{
Optimizing the Grinding Process for Ceramic Materials
}

\author{
Sam McSpadden \\ Oak Ridge National Laboratory \\ Precision Grinding \& Finishing in the \\ Global Economy - 2001
}

October 3, 2001

Chicago, IL

\section{What constitutes an "optimized" grinding process?}

This is not an easy question to answer. It's like asking "What's the optimum design for an automobile?"

Appearance?

Size?

Power?

Fuel Economy?

Overall Cost of Ownership?
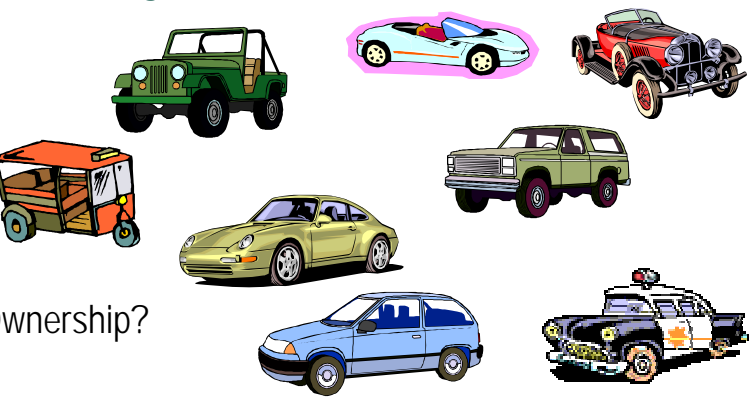

Although all of the above factors may be important, function and convenience also play a part in the decision making process. 
From a strictly economic standpoint, a grinding process can be optimized by minimizing total production cost, consistent with acceptable workpiece quality.

- Cost of fixtures, part loading and unloading

- Costs of coolant, including cleaning, handling, and disposal

- Machining cost

- Dressing costs

- Labor and materials

- Lost production time

- Wheel consumption

The degree of optimization achievable is often limited by real-world constraints

- Available equipment

- Machine power

- Wheel wear

- Workpiece constraints

- Tolerances

- Surface finish

- Thermal damage

- Mechanical properties 
We should examine the overall grinding process before attempting to adjust individual process elements.

- Define the workpiece requirements.

- Analyze the grinding process in terms of overall cost and required production rates. (This may not be easy to do in initial planning stages before operational data are available.)

The term process element is used to describe a fundamental characteristic of the grinding process, which may be fixed or variable, controlled or observed.

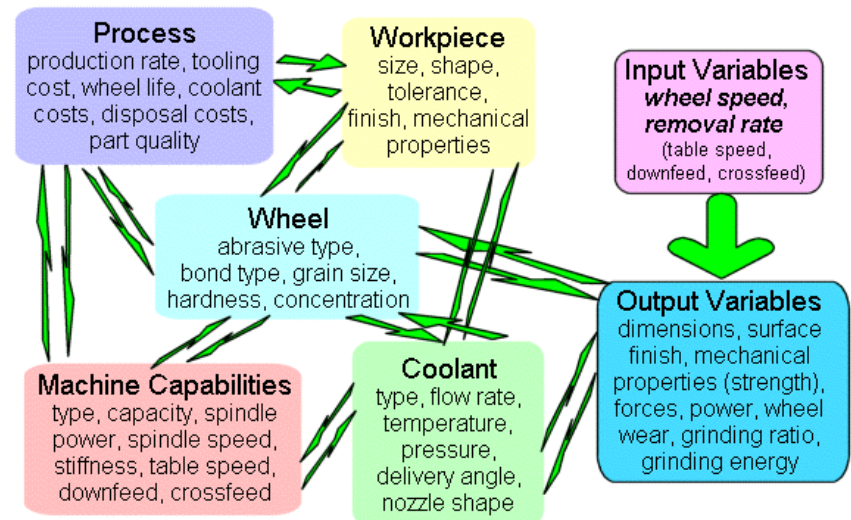




\section{Workpiece requirements...}

- Define the minimum acceptable workpiece quality in terms of size, geometric form, surface finish, and mechanical properties.

- Define the maximum achievable workpiece quality in those same terms.

- The optimized grinding process will consistently produce workpieces somewhere between minimum acceptable and maximum achievable quality.

- Frequently, aiming at the latter will drive your process toward optimization

\section{Grinding process considerations...}

- Availability of suitable equipment

- Grinding cycle time

- Cost of wheel truing and dressing

- Initial cost of wheels

- Frequency of truing/dressing/changing wheels

- Initial and ongoing coolant costs

- Waste disposal costs

- Equipment down time due to maintenance and processing of consumable media (coolant and wheels) 


\section{Having defined workpiece and overall process requirements, we can now begin to focus on the grinding process.}

- Machine type (Cylindrical, Centerless, Surface, Creep Feed, Other)

- Grinding wheel

- Abrasive Type (superabrasive diamond or CBN, silicon carbide, aluminum oxide)

- Bond (resin, vitreous, metal)

- Coolant (Water Dilutable, Synthetic, Mineral Oil, Other)

Having defined the grinding process in general terms, we can now begin to optimize the process. There are two different approaches available for process optimization.

- The analytical approach, based on theoretical equations and some empirical information.

- The experimental approach, which draws on the body of analytical and empirical information available, but also relies on instrumented grinding tests. 
The Analytical Approach to process optimization...

- Attempts to define and model the grinding process in terms of material removal at the abrasive grit level

- Treats each active abrasive grain as a miniature cutting tool; which removes material by sliding, plowing, and eventually forming a chip.

- The most important process elements are abrasive grit size and distribution (number of cutting points per unit area), workpiece speed, wheel speed, and depth of cut.)

The Analytical Approach to process optimization...

- Attempts to quantify the effects of coolant, abrasive characteristics (bond system, hardness, grain friability, and concentration), and temperature.

- Uses computer models to deal with the inherently random nature of grinding wheels. 
The following equation* combines the number of cutting points per unit area, workpiece speed, wheel speed, wheel diameter, and depth of cut into a single quantity called the undeformed chip thickness (sometimes called the "grit-depth-of-cut).

$$
h_{m}=\left[\frac{4}{C r}\left(\frac{V_{w}}{V_{s}}\right)\left(\frac{a}{d_{e}}\right)^{\frac{1}{2}}\right]^{\frac{1}{2}}
$$

* S. Malkin, Grinding Technology, Theory and Applications of Machining with Abrasives; p. 61. John Wiley and Sons, New York, 1989.

Although most of the terms in the equation can be easily measured and controlled, " $r$ " and "C" are less straightforward.

$$
h_{m}=\left[\frac{4}{\operatorname{Cr}}\left(\frac{V_{w}}{V_{s}}\right)\left(\frac{a}{d_{e}}\right)^{\frac{1}{2}}\right]^{\frac{1}{2}}
$$

" $C$," the number of abrasive grains per unit area, can best be determined by direct or indirect measurement. Values between 10 and 20 are commonly used, with lower numbers giving more conservative estimates of the chip thickness. The value of " $r$ " requires an assumption about the shape of the "typical" abrasive particle." 
Typical values of "C" were obtained at ORNL for five different grit sizes.

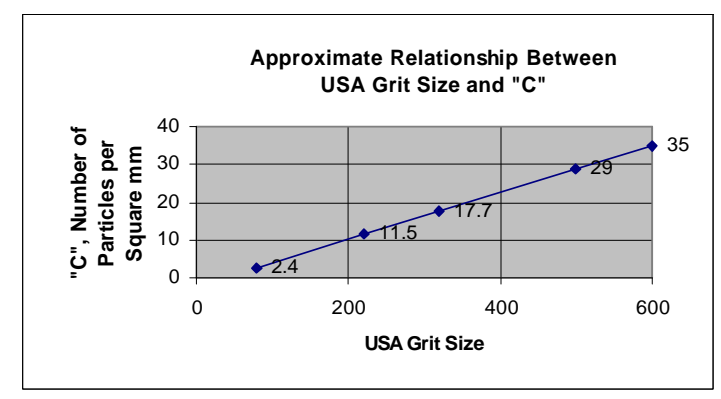

Wheel Surfaces were replicated in dental mold material and examined under magnification. All wheels were 100 concentration, commercially available, resinbond diamond grinding wheels obtained from a single vendor.

\section{The undeformed chip thickness provides a} better correlation with the following process elements than the overall depth of cut value.

- Grinding forces (normal and tangential)

- Surface finish

- Surface temperatures

- Wheel wear 


\section{The Experimental Approach to Process Optimization...}

- Makes use of available analytical tools and existing base of empirical knowledge

- Focuses on the macroscopic or system-level "goals" rather than trying to control the process at the individual abrasive grain level.

- Is often constrained by workpiece requirements, performance characteristics of the equipment, and the random nature of grinding wheels.

The Experimental Approach to Process Optimization...

- Simplifies experiments and minimizes the number of test runs by holding constant as many controllable process elements as possible.

- Studies the effects of changes in process elements that are easily measured, varied, and controlled 


\section{Process elements measured at ORNL usually consist of...}

- Grinding forces (tangential, normal, and lateral) measured with a Kistler dynamometer

- Spindle power - determined by monitoring the spindle motor current/phase relationship

- Acoustic emission - can be measured at rates of up to one million samples per second

- Spindle vibration - can be measured and related to angular wheel position

Instrumented grinders available at the Machining and Inspection Research User Center at ORNL for use in process optimization ...

- Conventional light-duty surface grinders (3)

- Creep feed surface grinders (2)

- Cylindrical Grinder (1)

- Vertical 3-axis CNC grinder (1)

- Smaller special-purpose machines

- Tripod grinder

- Grindability test system (uses abrasive belts)

- DedTru centerless grinding attachment

- High speed (90,000 RPM) low-torque spindle for small hole drilling 


\section{The primary process elements include...}

\section{- Wheel characteristics}

- Abrasive type (diamond, CBN, SiC, etc.)

- Bond type (resin, metal, vitrified)

- Grit size

- Concentration

- Friability, hardness, and openness

The primary process elements include...

- Coolant

- Chemical composition

- Concentration

- Delivery into the work zone 


\section{The primary process elements include...}

- Spindle speed

- Downfeed rate

- Table speed

- Grinding direction (Up grinding or Down grinding)

By varying one or more of the input variables, we can control or influence each of the following important process elements (output variables):

- Dimensional Accuracy

- Surface finish

- Material removal rate

- Grinding ratio

- Grinding energy/grinding efficiency

- Mechanical strength 


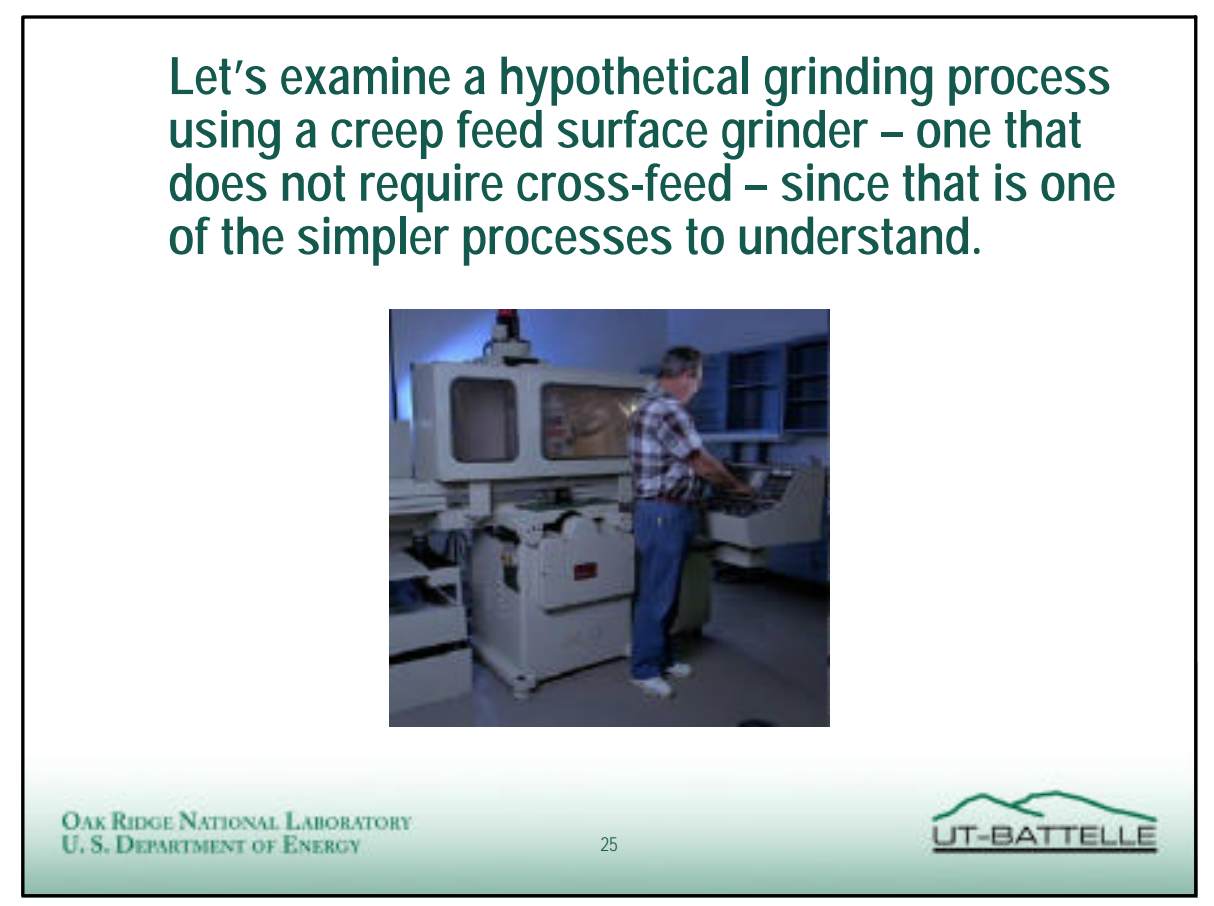

The operating envelope for the Nicco creep feed grinder is shown below.

\begin{tabular}{|l|l|}
\hline Spindle speed & 500 to 3500 RPM \\
\hline Spindle motor power & $5.6 \mathrm{~kW}$ (7.5 HP) \\
\hline Table speed & $\begin{array}{l}\text { Variable, from } 2.5 \text { to } 1000 \mathrm{~mm} / \text { minute } \\
\text { (0.1 to } 40 \text { inch / minute) }\end{array}$ \\
\hline Wheel diameter & 175 to $200 \mathrm{~mm}$ (7 to 8 inch, 2-inch bore) \\
\hline
\end{tabular}


Assume that the workpiece material is a simple rectangular test coupon made from a magnesium stabilized zirconia (MSZ).

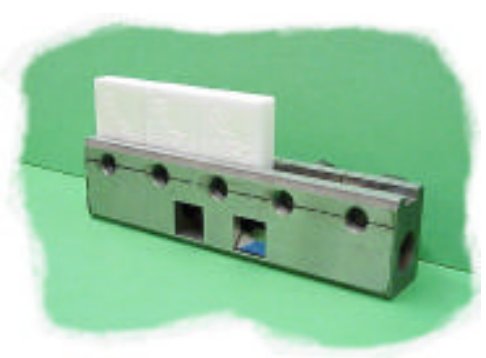

\section{PROCESS REQUIREMENTS}

- High removal rates

- Good surface finish

- Low wheel wear

- No reduction in mechanical properties due to grinding

The MSZ material automatically narrows our choice of wheel types (based on the existing body of empirical knowledge).

Wheel Characteristics (Possible choices are diamond, CBN, or SiC)

$X \quad$ - SiC is not widely used for grinding zirconia

- When used, generally used for roughing operations where dimensional accuracy is not a major concern

$X \quad$ CBN is known to perform well on the workpiece material

- More expensive than diamond on a carat-per-carat basis

- No performance advantage over diamond

- Diamond is known to perform well on the workpiece material 
We can refine our wheel selection further, again based largely on empirical knowledge.

- Resin bond selected due to availability, ease of truing and dressing

- Largest diameter wheel that will run on the machine

- To eliminate the cross feed variable, we choose a wheel that is at least as wide as the workpiece

- By choosing a wheel that is wider than the workpiece, we simplify the measurement of wheel wear.

(An 8-inch diameter, $1 / 2$ inch wide wheel of type ASD220R100B99-1/8 wheel was selected as an appropriate starting point (220-grit, R-grade, 100 concentration)

Now that we have the machine, material, and wheel selected, we look for input variables that can be held constant.

- Choose the maximum spindle speed consistent with safe operating speed for the grinding wheel

-Reduces undeformed chip thickness

-Reduces grinding forces

-Causes wheel to act "harder"

- Choose both Up and Down grinding (i. e., material will be removed in both directions of table travel) 
Coolant selected for this particular study was again based on empirical knowledge, as well as personal preference.

- Should provide good lubricity characteristics and carry away heat

- Water soluble

- Concentration easily adjusted and maintained (start with 20:1 mix)

- No special protective equipment required to handle

- Easily filtered and reused

- Relatively low disposal costs

- Should be delivered directly to the contact zone through a pressurized nozzle on both sides of the wheel in the plane of wheel rotation

(We used CIMTECH 500, but there are numerous other products that should give similar performance characteristics.)

We are left with two easily controlled input variables, downfeed and table speed. By varying these, we can observe the effect on...

- Specific Material removal rate (Q')

- Grinding ratio (G)

- Grinding energy (U)

- Normal and Tangential Grinding Forces $\left(F_{n}\right.$ and $\left.F_{t}\right)$

- Surface finish

- Dimensional Accuracy

- Mechanical strength 
The relationship between table speed, downfeed, and specific material removal rate ( $\left.Q^{\prime}\right)$ is straightforward, but maximum values need to be determined experimentally.

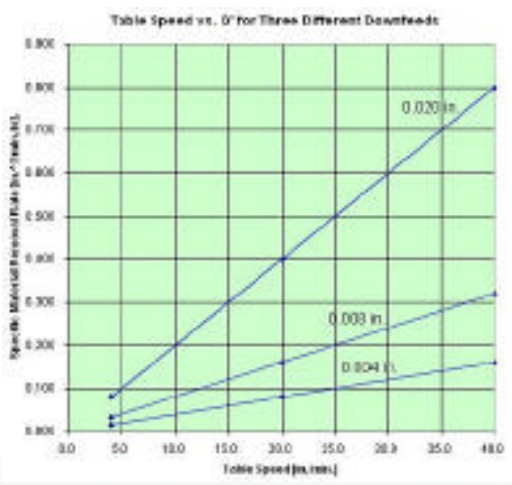

\section{A practical approach for determining the maximum table speed and downfeed...}

- Start with a freshly trued and dressed wheel.

- Use a rotary hydraulic brake-controlled diamond truing wheel.

- Follow by dressing to the manufacturer's recommendations.

- Select an aggressive downfeed and a very slow table speed.

- Grind several passes on the test specimen.

- Observe spindle power.

- Power consumption should be well within the rated power of the spindle.

- Observe tangential and normal forces.

- Forces should be quite low, but large enough to see a difference when the wheel is on and off the part.

- Forces should be slightly higher during up grinding portion of the cycle than the down grinding portion.

- Increase or decrease the table speed as necessary to achieve these force and power conditions. 
Wheel wear is non-linear, and is strongly influenced by the condition of the wheel.

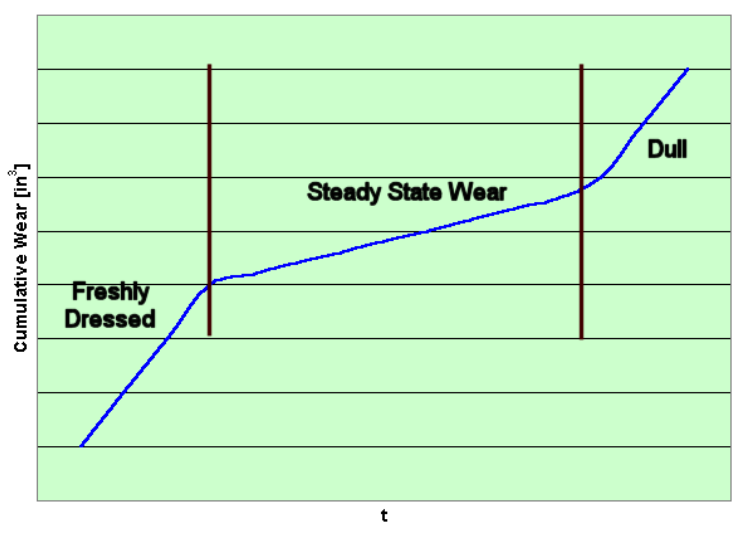

Data collected on a freshly dressed grinding wheel are likely to be of little value until the wheel undergoes a small amount of initial wear.

- Abrasive grains are extremely sharp after dressing

- Tangential and normal forces may be deceptively low

- Spindle power may also be low

- The bond system has been removed to give maximum grain exposure

- This can result in excessive grain pullout

- The wheel may appear to give very good initial results

- Active grains develop initial wear flats very quickly

- Tangential and normal forces should gradually increase as the wheel begins to wear.

- Spindle power should also increase slightly during this wearing in process. 
Using the "stabilized" grinding wheel, gradually increase the table speed and monitor the process.

- Spindle power and grinding forces should increase as table speed increases, but should remain constant when observed for several grinding passes.

- Forces and power may be slightly higher for up grinding than for down grinding.

- Continue increasing the table speed until...

- The target specific material removal rate is reached, or

- The spindle power consumption approaches the maximum rated continuous operating power level.

Now that we have established a range of table speeds and downfeeds to be investigated, the process can be further "optimized."

\begin{tabular}{|c|c|c|c|}
\hline & $\begin{array}{c}\text { High } \\
\text { Downfeed }\end{array}$ & $\begin{array}{c}\text { Intermediate } \\
\text { Downfeed }\end{array}$ & $\begin{array}{c}\text { Low } \\
\text { Downfeed }\end{array}$ \\
\hline $\begin{array}{c}\text { High } \\
\text { Table Speed }\end{array}$ & $\mathrm{X}$ & $\mathrm{X}$ & $\mathrm{X}$ \\
\hline $\begin{array}{c}\text { Low } \\
\text { Table Speed }\end{array}$ & $\mathrm{X}$ & $\mathrm{X}$ & $\mathrm{X}$ \\
\hline
\end{tabular}




\section{A spreadsheet that incorporates commonly used formulas is strongly recommended.}

- Volume of workpiece material removed

- Material removal rate and specific material removal rate

- Radial change in wheel size (volume of wheel material worn away during grinding)

- Grinding Ratio

- Spindle power

- Tangential and Normal grinding forces

- Specific Grinding Energy

Calculating the volume of workpiece material removed can be done in either of two ways...

- Count the number of grinding passes and multiply by the depth-of-grind times the width of the test specimen

- Measure the part before and after grinding.

(The latter method can reveal mechanical stiffness problems in the equipment.) 


\section{Calculating the material removal rate and specific material removal rate...}

- Material removal rate is simply the volume of workpiece material removed divided by the time the wheel is in contact with the workpiece.

- Material removal rate is often expressed as specific material removal rate (Q'), or volume of material removed per unit time per unit of wheel width.

\section{Radial change in wheel size (volume of wheel material worn away during grinding)...}

Starting with a conditioned wheel, before the grinding test, position a razor blade or a thin plastic shim beneath the grinding wheel, parallel to the spindle axis.

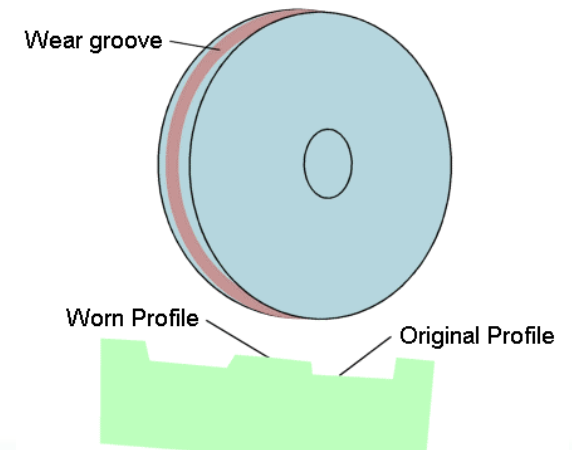

- Plunge the wheel into the blade or shim to capture the initial profile of the wheel.

- After the grinding test, capture the final profile of the wheel in the same manner.

- Use a stylus surface profiler, comparator, or CMM to measure and compare the two profiles.

- Calculate cross-sectional area

- Convert to volume 


\section{Calculate the grinding ratio, spindle power consumption, and specific grinding energy.}

\section{- Grinding Ratio}

- Divide the volume of workpiece material removed by the change in volume of the grinding wheel attributable to wear.

- Spindle power

- Measure directly from spindle power supply

- Calculate in terms of tangential force and wheel surface speed $\left(P=F_{t} V_{w}\right)$.

- Specific Grinding Energy

- Approximate by dividing the material removal rate by the average power consumed by the spindle.

Once all tests have been run, it us usually straightforward to select the set of conditions that gave the best overall results in terms of...

- Highest grinding ratio

- Fastest removal rate

- Best dimensional accuracy and surface finish

- Acceptable mechanical properties

- Lowest energy consumption

As with most real-world processes, it may be necessary to compromise in order to achieve acceptable values for all process elements. 


\section{Summary...}

- There is probably no such thing as an optimized grinding process that stays optimized, but we should still strive for one.

- There is a strong need for standardized test methodologies that can be conducted in a production environment at reasonable costs and without sophisticated instrumentation.

- There is a need for better analytical models whose results closely match real-world grinding processes.

- Accurate measurement of wheel performance and wheel wear is a key enabling technology that needs further work and standardization. 